\title{
Potent Heterogeneous Catalyst for Low Temperature Selective Oxidation of Cyclohexanol by Molecular Oxygen
}

\author{
Haroon ur Rashid, ${ }^{1}$ M. Sohail Ahmad, ${ }^{2}$ Mohammad Sadiq, ${ }^{2}$ and Razia Aman ${ }^{2}$ \\ ${ }^{1}$ Department of Chemistry, Sarhad University of Science and Information Technology, Peshawar, Pakistan \\ ${ }^{2}$ Department of Chemistry, University of Malakand, Chakdara 18800, Pakistan \\ Correspondence should be addressed to Mohammad Sadiq; sadiq@uom.edu.pk
}

Received 8 August 2016; Accepted 10 November 2016

Academic Editor: Shiran Zhang

Copyright (c) 2016 Haroon ur Rashid et al. This is an open access article distributed under the Creative Commons Attribution License, which permits unrestricted use, distribution, and reproduction in any medium, provided the original work is properly cited.

Platinum supported on zirconium dioxide catalyst was prepared by standard method and characterized by SEM, EDX, XRD, BET surface area and pore size analyzer, and FT-IR. The catalyst was screened for its catalytic activity in a model reaction, selective oxidation of cyclohexanol. The only one major product, cyclohexanone $31 \%$, with $99.8 \%$ selectivity was obtained. Experimental data was analyzed through different kinetic models and we deduced that the reaction follows Langmuir-Hinshelwood mechanism. The apparent activation energy for the model reaction was calculated as $45 \mathrm{~kJ} / \mathrm{mole}$. The catalyst was regenerated several times with same efficiency.

\section{Introduction}

The oxidation reaction involving the conversion of alcohol with molecular oxygen to the corresponding carbonyl compounds has vital role in laboratory as well as in chemical industries $[1,2]$. It provides a green rout for the production of fine chemicals [3]. Cyclohexanone is quite important intermediate in the synthesis of caprolactam which is used in the production of nylon 6 and nylon 6,6. It is used as a solvent in a coating process, as well as a plasticizer, food additive, and pharmaceutical. Besides this some other applications of cyclohexanone are being as raw materials in the production of insecticides and herbicides [4-6]. Due to the importance of this catalytic conversion the researchers are interested in developing such a pathway which is nontoxic and simple with low cost and high \% yield.

Commonly, different kinds of methods are known for the large scale production of cyclohexanone by the conversion of cyclohexanol $[7,8]$. Nevertheless, the new methods are gaining much attention of the researchers, because of the importance of the desired products. Formally, the researchers made efforts for the catalytic transformation of alcohol to the corresponding product, by the use of strong oxidants such as manganese, chromium complexes, mineral acids, tert-butyl hydroperoxide, ruthenium oxide, selenium dioxide, hydrogen peroxide, nitric acid, permanganates, and molecular oxygen. These reagents are toxic, corrosive, expensive, and unstable in normal condition and may produce by-products [9-11]. Hence, to overcome these problems it is required to change the conventional route of oxidation heterogeneous catalyst (noble metal catalyst by solid support) and molecular oxygen as an oxidant which are much cleaner technologies [12]. In the heterogeneous system, we can recover and reuse the catalyst.

The $\mathrm{Ru}$ hydroxyapatite, $\mathrm{Pd}$ hydroxyapatite, and $\mathrm{Ru} / \mathrm{Al}_{2} \mathrm{O}_{3}$ are reported heterogeneous catalysts in the literature [13]. However, these catalysts work only at elevated reaction condition which is undesirable. Parentis et al. reported the oxidation of cyclohexanol in the presence of chromium supported on silica by tert-butyl hydroperoxide as an oxidant; approximately $40 \%$ conversions were achieved but the oxidant is very toxic. Various gold based heterogeneous catalysts have been reported such as $\mathrm{Au}$ supported on $\mathrm{CeO}_{2}, \mathrm{Au}-\mathrm{Pd}$ on titanium dioxide, and $\mathrm{Au} / \mathrm{Ga}_{3} \mathrm{Al}_{3} \mathrm{O}_{9}$ but these catalysts require high reaction temperature [14-17].

Currently, a zirconium dioxide is used as catalyst and catalyst support and gains much attention, because of its high 
thermal stability and the presence of both acidic and basic characters on its surface. As a support, zirconium dioxide has been superior to others [18, 19]. The sites (acidic and basic) coexist on the surface of zirconia and can interact both cooperatively and independently, based on reactions. Nakano and coworkers studied the surface properties of zirconia [20]. Metals doped zirconia has been reported for different type of reactions such as isomerization and oxidation [19]. In the present study, for the first time we have used platinum supported on zirconium dioxide as a catalyst for oxidation of cyclohexanol to cyclohexanone using molecular oxygen as an oxidant.

\section{Experimental}

2.1. General. Octa-hydrated zirconium oxychloride, $\mathrm{PtCl}_{4}$, cyclohexanol, and cyclohexanone were purchased from Merck and GPR (BDH), respectively. All the chemicals were of high purity and further purification was not essential. Double distilled water was used in this whole work. The gases (nitrogen and oxygen) used in the present study were bought from BOC Pakistan, Ltd. For further purification of the gases, nitrogen and oxygen, suitable filters (C.R.S.Inc.202268, C.R.S.Inc.202223) were used, respectively.

2.2. Preparation of the Catalyst. Monoclinic zirconia was used as a support for the platinum catalyst, which was prepared from 0.25 molar aqueous solution of $\mathrm{ZrOCl}_{2} \cdot 8 \mathrm{H}_{2} \mathrm{O}$ by controlled titration against ammonia. White dense precipitate of $\mathrm{Zr}(\mathrm{OH})_{4}$ was washed in modified soxhlet apparatus for attaining $\mathrm{Cl}^{-}$free sample. The precipitate was then dried in an oven, grinded, meshed (passing from 170 and retained at 200 US standard mesh sieves), and calcined at $1023 \mathrm{~K}$ in the muffle furnace at a heat ramp of $273.5 \mathrm{~K} / \mathrm{min}$ for $3 \mathrm{hrs}$.

The catalyst $\left(0.01 \mathrm{wt} \% \mathrm{Pt} / \mathrm{ZrO}_{2}\right)$ was prepared by incipient wetness technique. $2 \mathrm{~mL}$ aqueous solution of $\mathrm{PtCl}_{4}(5.1 \times$ $10^{-5} \mathrm{M}$ ) was added to $9.99 \mathrm{~g}$ of zirconia. The paste of the prepared sample was dried overnight in an oven at $383 \mathrm{~K}$, grinded, and meshed (passing via 170 and retained at 200, US standard mesh sieves). The platinized zirconia was thus obtained after calcination at $1023 \mathrm{~K}$ at a rate of $273.5 \mathrm{~K} / \mathrm{min}$ for $3 \mathrm{hrs}$. The resulting catalyst was stored in desiccator.

2.3. Characterization of the Catalyst. $0.01 \mathrm{wt} \% \mathrm{Pt} / \mathrm{ZrO}_{2}$ was characterized by modern techniques. SEM images of the sample were recorded on SEM "model: JSM5910; manufacturer: JEOL, Japan; energy: $30 \mathrm{KV}$; magnification (Max): 300,000x; resolving power (Max): $2.3 \mathrm{~nm}$; sample: solid (powder or bulk)." XRD of the sample was determined by X-ray diffractometer "model: JDX-3532; make: JEOL, Japan; voltage: $20-40 \mathrm{kV}$; current: $2.5-30 \mathrm{~mA}$; X-rays: $\mathrm{CuKa}(l=$ $1.5418 \AA$ ); 2 theta-range: 0 to $160^{\circ}$; sample: solid (powder or bulk)." EDX of the catalyst was performed on Energy Dispersive Spectroscopy "INCA200/Oxford Instruments, UK; analysis range: boron to uranium." BET surface area of the samples was analyzed by surface area and pore size analyzer "model: NOVA2200e; make: Quantachrome, USA; adsorbate: nitrogen; sample: solid (powder).” FT-IR spectra of the catalysts were recorded by Fourier Transform Infrared Spectrophotometer "IR Prestige, Shimadzu Japan."

2.4. Catalytic Oxidation of Cyclohexanol. Solvent-free liquid phase oxidation of cyclohexanol was performed in a threenecked single walled reactor connected with a reflux condenser and a magnetic stirrer. The reactor was wrapped by a heating cord linked to Digi-Sense Temperature Controller (Cole-Parmer, USA) while temperature was controlled by a $\mathrm{K}$ type Thermocouple located between the reactor and the heating cord. In a typical experiment the reactor was charged with $10 \mathrm{~mL}$ of cyclohexanol, and the catalyst was $0.03-0.2 \mathrm{~g}$. The temperature of the mixture was raised from 323 to $353 \mathrm{~K}$ while the oxidant (molecular oxygen) was bubbled in the mixture for $0.25-6$ hrs. Gravimetric analysis and UV spectrophotometer were used for the progress of reaction run. The reaction mixture was analyzed by GC (PerkinElmer, Clarus 580, USA) equipped with FID detector.

\section{Results and Discussion}

3.1. Characterization of the Catalyst. The particle size of the catalyst was in the range of 74-88 $\mu$ according to US standard sieves while the surface area of zirconia and $0.01 \mathrm{wt} \% \mathrm{Pt} / \mathrm{ZrO}_{2}$ was $52.7 \mathrm{~m}^{2} / \mathrm{g}$ and $50.4 \mathrm{~m}^{2} / \mathrm{g}$, respectively. Decrease in the surface area of platinized zirconia is perhaps due to the blockage of surface pores of zirconia by platinum. SEM photographs at different magnification clearly reveal the presence of platinum particles on the surface of support as shown in Figure 1. The EDX spectrum of the platinized zirconia is presented in Figure 2, which shows that the catalyst only consists of platinum and zirconia in its structure.

$\mathrm{X}$-ray diffraction spectrum of platinized zirconia is given in Figure 3. The sample shows the characteristic peaks due to zirconia that originated from crystal phase and can be seen at $2 \theta=28.2^{\circ}$ and $2 \theta=31.4^{\circ}$ belonging to monoclinic phase of zirconia [21] while peaks responsible for platinum were not seen in the XRD spectrum due to low loading. The infrared spectra of fresh monoclinic zirconia have a sharp band at $746 \mathrm{~cm}^{-1}$ which is responsible for monoclinic phase zirconia and has a good agreement with XRD results, while spectra of $\mathrm{Pt} / \mathrm{ZrO}_{2}$ being used for oxidation of cyclohexanol to cyclohexanone show the presence of peaks responsible for $\mathrm{C}=\mathrm{O}(1720)$ and $\mathrm{O}-\mathrm{H}\left(3415-3444 \mathrm{~cm}^{-1}\right)$ groups which reflect the presence of product material on the surface of catalyst as presented in Figure 4.

3.2. Effect of Various Reaction Variables. Usually the oxidation reaction was carried out in the presence of platinized zirconia $0.1 \mathrm{~g}$ and cyclohexanol $10 \mathrm{~mL}$ with molecular oxygen using three-necked single walled batch reactor. Although blank test was carried out in the same set of reaction parameters without catalyst loading, this shows the absence of spontaneous oxidation of cyclohexanol with molecular oxygen. Similarly, pure monoclinic zirconia was also checked for its catalytic activity with optimal reaction conditions (catalyst: $0.1 \mathrm{~g}$, time: $6 \mathrm{hrs}$, temperature: $353 \mathrm{~K}$, flow of oxygen: $40 \mathrm{~mL} / \mathrm{min}, \mathrm{pO}_{2}$ : 760 torr, and cyclohexanol: $10 \mathrm{~mL}$ ). 


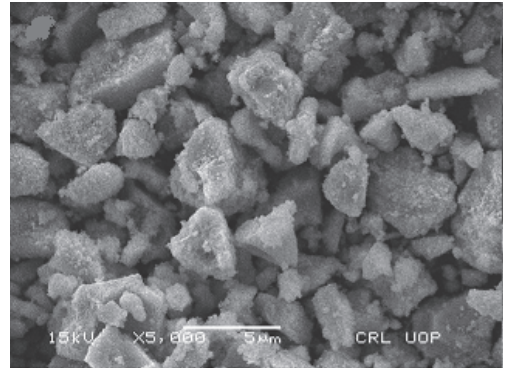

(a)

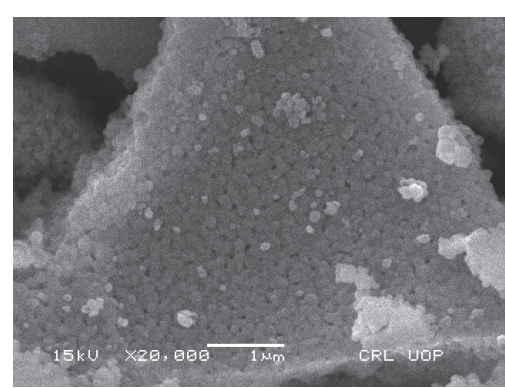

(b)

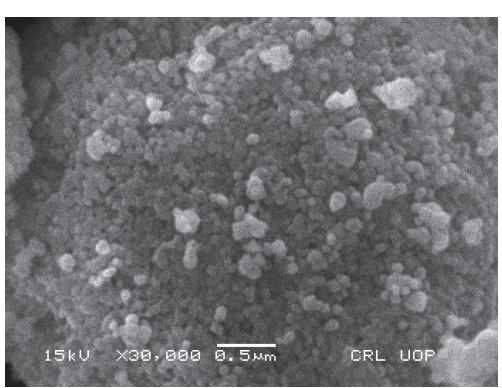

(c)

FIGURE 1: SEM images of $0.01 \mathrm{wt} \% \mathrm{Pt} / \mathrm{ZrO}_{2}$ as a catalyst.

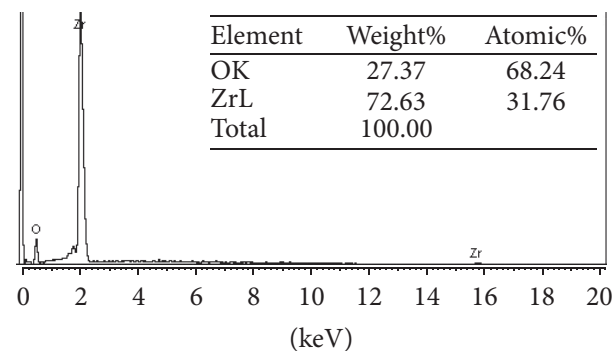

Full scale 1971 cts Cursor: $20.194 \mathrm{keV}$ (0 cts)

(a) $\mathrm{ZrO}_{2}$

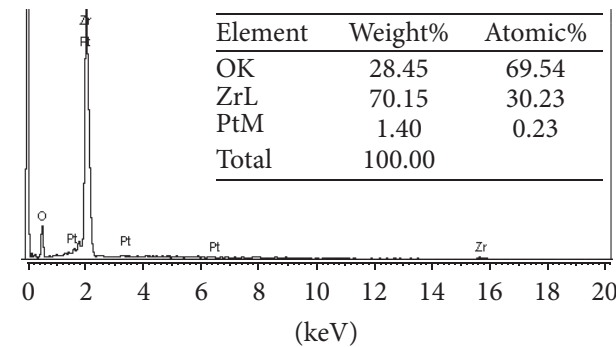

Full scale 1837 cts Cursor: $20.194 \mathrm{keV}(0 \mathrm{cts})$

(b) $\mathrm{Pt} / \mathrm{ZrO}_{2}$

Figure 2: EDX spectra of the (a) pure $\mathrm{ZrO}_{2}$ and (b) platinum supported on zirconia.

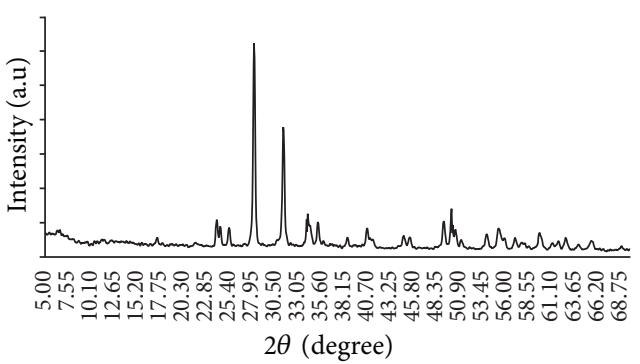

FIGURE 3: X-ray diffraction pattern of $0.01 \mathrm{wt} \% \mathrm{Pt} / \mathrm{ZrO}_{2}$ as a catalyst for oxidation of cyclohexanol to cyclohexanone.

Monoclinic zirconia was found active for catalytic oxidation of cyclohexanol and the results are quite consistent with reported value of activity and selectivity [22] as shown in Table 1.

The effect of time on conversion of cyclohexanol to cyclohexanone was monitored periodically; these experiments were carried out in the range of different time intervals up to 6 hours at atm pressure of oxygen and $333 \mathrm{~K}$ temperature in a solvent-free condition. Reaction duration has a linear effect on the conversion of cyclohexanol as presented in Figure 5. The maximum formation of desired product was achieved at 6 hours. Hence, 6 hours was selected to be the optimum reaction time. Furthermore, the effect of temperature, partial pressure of oxygen, and the amount of catalyst on the \% conversion were investigated.

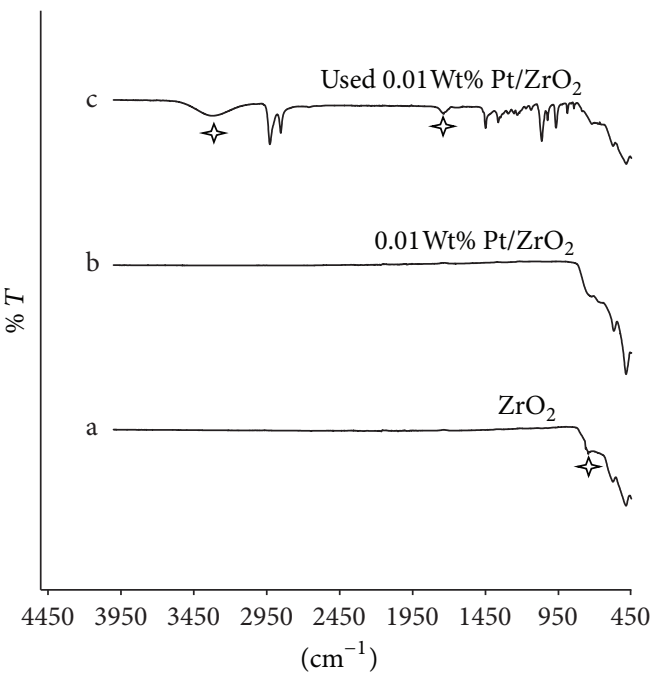

FIgURe 4: FT-IR spectra of (a) monoclinic $\mathrm{ZrO}_{2}$, (b) $\mathrm{Pt} / \mathrm{ZrO}_{2}$, and (c) after reaction unwashed $\mathrm{Pt} / \mathrm{ZrO}_{2}$.

To explore the effect of temperature on the oxidation processes of cyclohexanol in the presence of platinum supported on zirconia, the experiments were carried out at different temperature ranging from 323 to $353 \mathrm{~K}$ at 6 hours, flow, $40 \mathrm{~mL} / \mathrm{mn} ; \mathrm{pO}_{2}, 760$ torr; amount of catalyst, $0.1 \mathrm{~g}$; and cyclohexanol, $10 \mathrm{~mL}$. When temperature increases the percent conversion of cyclohexanol also increases, as presented in Figure 6. Activation energy of the oxidation 
TABLE 1: Oxidation of cyclohexanol to cyclohexanone by molecular oxygen.

\begin{tabular}{lcc}
\hline Catalyst & \% conversion & \% selectivity \\
\hline- & 0 & 0 \\
$\mathrm{ZrO}_{2}$ & 3.7 & $>99$ \\
$0.01 \mathrm{wt} \% \mathrm{Pt} / \mathrm{ZrO}_{2}$ & 31.23 & $>99$ \\
\hline
\end{tabular}

Reaction conditions: Cat, $0.1 \mathrm{~g}$; time: $6 \mathrm{hrs}$; temp., $353 \mathrm{~K}$; flow, $40 \mathrm{~mL} / \mathrm{min}$; $\mathrm{pO}_{2}, 760$ torr; cyclohexanol, $10 \mathrm{~mL}$; and stirring, $900 \mathrm{rpm}$.

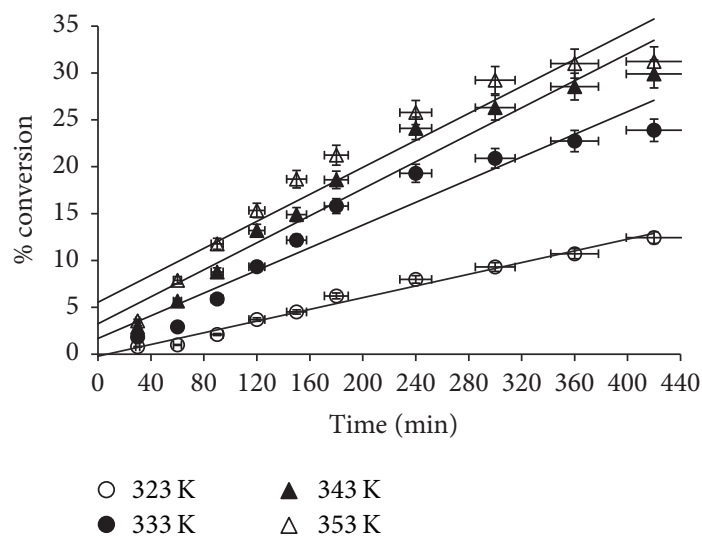

FIGURE 5: Effect of time for the conversion of cyclohexanol to cyclohexanone at different temperature. Reaction conditions: Cat, $0.1 \mathrm{~g}$; cyclohexanol, $10 \mathrm{~mL}$; flow, $40 \mathrm{~mL} / \mathrm{min}$; $\mathrm{pO}_{2}, 760$ torr; and stirring, $900 \mathrm{rpm}$.

reaction was calculated from the Arrhenius plot as shown in Figure 7. The apparent activation energy was calculated as $E_{a} \approx 45 \mathrm{~kJ} / \mathrm{mol}$. From the experimental activation energy, it can be emphasized that the reaction is kinetic controlled.

The \% conversion of cyclohexanol was affected by the amount of catalyst loaded to a batch reactor for the individual run; as the loading of catalyst increases the percent conversion of cyclohexanol increases linearly till $0.11 \mathrm{~g}$, while from $0.11 \mathrm{~g}$ to $0.2 \mathrm{~g}$ the increase of percent conversion was somewhat flattened as presented in Figure 8. Probably the observed trend was due to the availably of surface active sites.

The effect of the partial pressure of oxygen on the percent conversion of cyclohexanol was monitored in the range of 95-760 torr. The increase in percent conversion of cyclohexanol to cyclohexanone with increase of $\mathrm{pO}_{2}$ clarifies the fact that reaction is oxygen dependent and excludes the probability of oxidative dehydrogenation. Figure 9 reveals that the \% conversion of cyclohexanol to cyclohexanone increased substantially with the increase in the $\mathrm{pO}_{2}$ up to 570 torr, while further increase in the $\mathrm{pO}_{2}$ may not enhance further the percent conversion of cyclohexanol. This effect may be due to the surface courage of the catalyst with oxygen so that, at 760 torr $\mathrm{pO}_{2}$, the surface is almost completely covered, and no more oxygen could be accommodated on the surface [22].

3.3. Reaction Kinetics. For oxidation reaction of cyclohexanol three-well popular kinetics models, Mars-van Krevelen (MK), Eley-Rideal (E-R), and Langmuir-Hinshelwood (L-H)

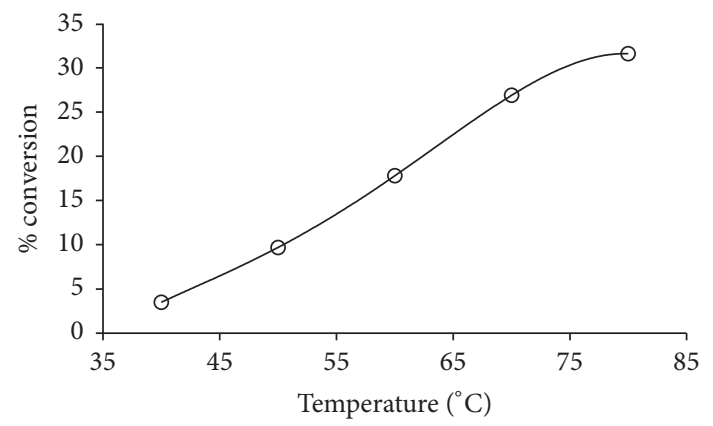

Figure 6: Effect of temperature on conversion of cyclohexanol to cyclohexanone. Reaction conditions: Cat, $0.1 \mathrm{~g}$; time, 6 hrs; cyclohexanol, $10 \mathrm{~mL}$; flow, $40 \mathrm{~mL} / \mathrm{min}$; $\mathrm{pO}_{2}, 760$ torr; and stirring, $900 \mathrm{rpm}$.

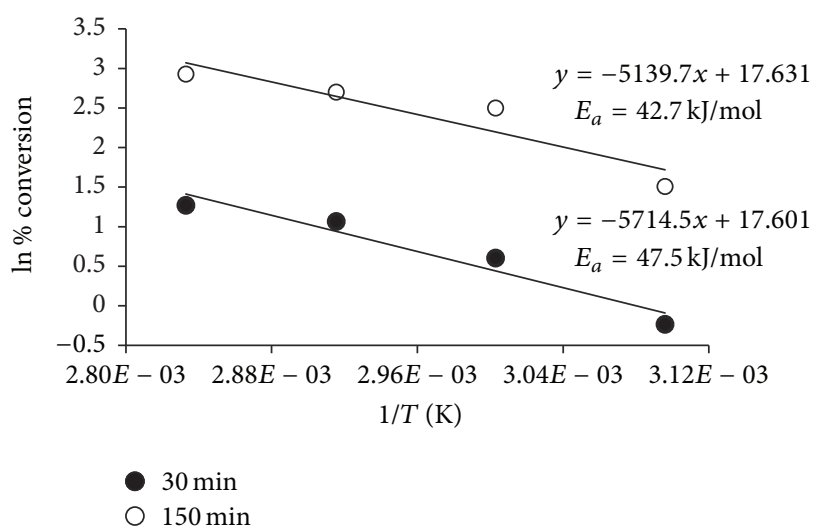

FIgURE 7: Arrhenius plot for the reaction of cyclohexanol to cyclohexanone at $30 \mathrm{~min}$ and $150 \mathrm{~min}$. Reaction conditions: Cat, $0.1 \mathrm{~g}$; cyclohexanol, $10 \mathrm{~mL}$; flow, $40 \mathrm{~mL} / \mathrm{min}$; $\mathrm{pO}_{2}, 760$ torr; and stirring, $900 \mathrm{rpm}$.

were modified and used for the elucidation of reaction kinetics. Among these three models only Langmuir-Hinshelwood (L-H) model was found appropriate for the proposed reaction. According to L-H mechanism, both cyclohexanol and oxygen first transport to the surface of the catalyst and get adsorbed. On the surface of the catalyst the adsorbed cyclohexanol and oxygen transform to products, desorb, and then transport away from the catalyst from the surface.

According to $\mathrm{L}-\mathrm{H}$ model, the rate of reaction is proportional to the fraction of the surface covered by reacting species, as

$$
\text { Rate }=K\left(\theta_{\mathrm{CyOH}} \theta_{\mathrm{O}_{2}}\right) \text {, }
$$

where $K$ is rate constant, $\theta_{\mathrm{CyOH}}$ is surface covered by cyclohexanol, and $\theta_{\mathrm{O}_{2}}$ is surface covered by molecular oxygen.

The rate equation for $\mathrm{L}-\mathrm{H}$ mechanism can be given as

$$
\text { Rate }=K \frac{K_{\mathrm{CyOH}}[\mathrm{CyOH}] K_{\mathrm{O}_{2}}\left[\mathrm{O}_{2}\right]_{\mathrm{g}}^{n}}{\left[1+K_{\mathrm{CyOH}}[\mathrm{CyOH}]+K_{\mathrm{O}_{2}}\left[\mathrm{O}_{2}\right]_{\mathrm{g}}^{n}\right]^{2}}
$$

(competitive), 


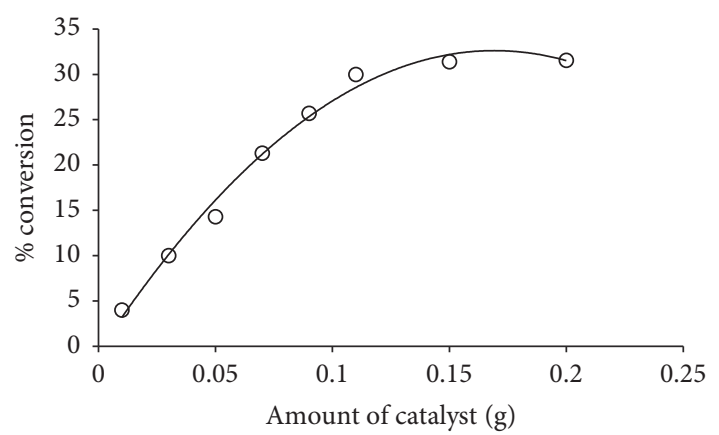

Figure 8: Effect on percent conversion of cyclohexanol to cyclohexanone by loading different amount of the catalyst. Reaction conditions: time, $6 \mathrm{hrs}$; temp., $353 \mathrm{~K}$; cyclohexanol, $10 \mathrm{~mL}$; flow, $40 \mathrm{~mL} / \mathrm{min} ; \mathrm{pO}_{2}, 760$ torr; and stirring, $900 \mathrm{rpm}$.

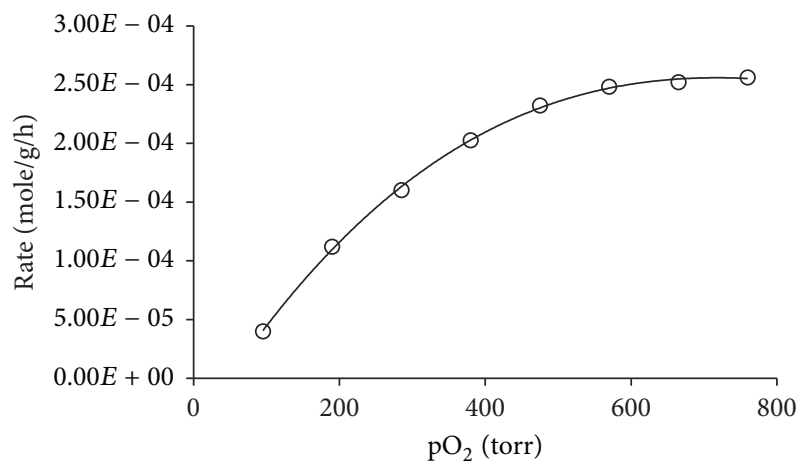

Figure 9: Effect of partial pressure of oxygen on oxidation of cyclohexanol. Reaction conditions: Cat, $0.1 \mathrm{~g}$; time, $6 \mathrm{hrs;}$ temp., $353 \mathrm{~K}$; cyclohexanol, $10 \mathrm{~mL}$; flow, $40 \mathrm{~mL} / \mathrm{min}$; and stirring, $900 \mathrm{rpm}$.

$$
\text { Rate }=K \frac{K_{\mathrm{CyOH}}[\mathrm{CyOH}] K_{\mathrm{O}_{2}}\left[\mathrm{O}_{2}\right]_{\mathrm{g}}^{n}}{\left(1+K_{\mathrm{CyOH}}[\mathrm{CyOH}]\right)\left(1+K_{\mathrm{O}_{2}}\left[\mathrm{O}_{2}\right]\right)}
$$

(non-competitive),

where $K_{\mathrm{CyOH}}$ and $K_{\mathrm{O}_{2}}$ are the adsorption equilibrium constants for cyclohexanol and oxygen, respectively. Equation (2) represents competitive adsorption, while (3) represents noncompetitive adsorption. And $n=1$ or $n=1 / 2$ is used for nondissociative or dissociative adsorption of oxygen, respectively. Using $n=1$ at constant $\mathrm{CyOH}$ concentration in (2) and (3) will be changed by putting together the entire constants as (4) and (5)

$$
\begin{aligned}
& \text { Rate }=\frac{a b\left[\mathrm{O}_{2}\right]}{\left[c+b\left[\mathrm{O}_{2}\right]\right]^{2}}, \\
& \text { Rate }=\frac{a b\left[\mathrm{O}_{2}\right]}{\left(1+b\left[\mathrm{O}_{2}\right]\right)} .
\end{aligned}
$$

The experimental data was subjected to the kinetic analysis using Microsoft office 2010 software. The experimental data was applied to (5) at constant partial pressure of oxygen 570 torr and temperature $353 \mathrm{~K}$ as shown in

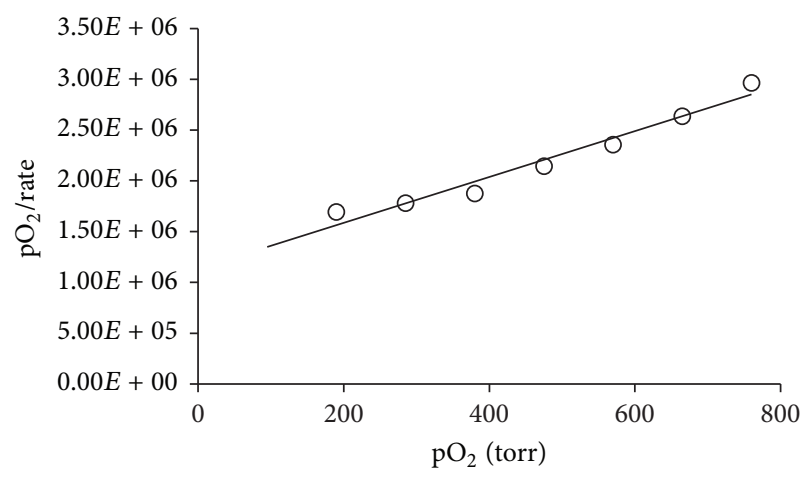

FIGURE 10: Plot of Langmuir-Hinshelwood noncompetitive model for the oxidation of cyclohexanol to cyclohexanone.

Figure 10, which shows that the noncompetitive LangmuirHinshelwood mechanism gives better fit with the regression value $\left(R^{2}=0.961\right)$.

The TON and TOF for the oxidation of cyclohexanol at $353 \mathrm{~K}$ in solvent-free condition were 697.26 and $116 \mathrm{~h}^{-1}$, respectively, which are superior to the reported active catalyst manganese oxide for oxidation of alcohol [23].

\section{Conclusion}

$0.01 \mathrm{wt} \% \mathrm{Pt} / \mathrm{ZrO}_{2}$ was found to be active catalyst in the oxidation of cyclohexanol to cyclohexanone in the presence of molecular oxygen as an oxidant. The catalyst was found more efficient and selective for the proposed model reaction than the reported catalyst. This heterogeneous system can be considered as an eco-friendly chemical process due to the use of clean oxidant, mild reaction conditions, and easily separable and reusable catalyst.

\section{Competing Interests}

The authors declare that there is no conflict of interests regarding the publication of this paper.

\section{Acknowledgments}

The authors greatly acknowledge the financial support from Higher Education Commission of Pakistan, Pakistan Science Foundation, and University of Malakand, respectively.

\section{References}

[1] C. Parmeggiani and F. Cardona, "Transition metal based catalysts in the aerobic oxidation of alcohols," Green Chemistry, vol. 14, no. 3, pp. 547-564, 2012.

[2] P. Rajendran, T. Divya, P. Bashpa, and K. Biudas, "Kinetics of oxidation of benzyl alcohol by molecular oxygen using manganese oxide supported activated carbon with phase transfer catalyst," Journal of Chemical and Pharmaceutical Sciences, pp. 22-27, 2016.

[3] J. Zhu, J. L. Faria, J. L. Figueiredo, and A. Thomas, "Reaction mechanism of aerobic oxidation of alcohols conducted 
on activated-carbon-supported cobalt oxide catalysts," Chemistry-A European Journal, vol. 17, no. 25, pp. 7112-7117, 2011.

[4] Y. K. Vyawahare, V. R. Chumbhale, S. A. Pardhy, V. Samuelb, and A. S. Aswara, "Gas-phase oxidant-free oxidation of cyclohexanol over $\mathrm{V}_{2} \mathrm{O}_{5}-\mathrm{MoO}_{3}-\mathrm{M}_{2} \mathrm{O}(\mathrm{M}=\mathrm{Na}, \mathrm{K}, \mathrm{Cs})$ catalysts," Indian Journal of Chemical Technology, vol. 17, no. 1, pp. 43-49, 2010.

[5] M. Hasanzadeh, G. Karim-Nezhad, M. G. Mahjani et al., "A study of the electrocatalytic oxidation of cyclohexanol on copper electrode," Catalysis Communications, vol. 10, no. 3, pp. 295-299, 2008.

[6] L. Chen, T. Zhou, L. Chen et al., "Selective oxidation of cyclohexanol to cyclohexanone in the ionic liquid 1-octyl-3-methylimidazolium chloride," Chemical Communications, vol. 47, no. 33, pp. 9354-9356, 2011.

[7] A. Sakthivel and P. Selvam, "Mesoporous (Cr)MCM-41: a mild and efficient heterogeneous catalyst for selective oxidation of cyclohexane," Journal of Catalysis, vol. 211, no. 1, pp. 134-143, 2002.

[8] Y. Chang, T. Jiang, B. Han et al., "Aerobic oxidation of cyclohexanol to cyclohexanone in compressed $\mathrm{CO}_{2}$ and liquid solvents," Industrial and Engineering Chemistry Research, vol. 42, no. 25, pp. 6384-6388, 2003.

[9] M. Salavati-Niasari, E. Zamani, M. R. Ganjali, and P. Norouzi, "Synthesis, characterization and liquid phase oxidation of cyclohexanol using tert-butylhydroperoxide over host (zeoliteY)/guest (copper(II) complexes of 12- and 13-membered diaza dioxa Schiff-base macrocyclic ligand) nanocomposite materials (HGNM)," Journal of Molecular Catalysis A: Chemical, vol. 261, no. 2, pp. 196-201, 2007.

[10] R. Sheldon, Metal-Catalyzed Oxidations of Organic Compounds: Mechanistic Principles and Synthetic Methodology Including Biochemical Processes, Elsevier, 2012.

[11] L. I. Simandi, "Dioxygen activation and homogeneous catalytic oxidation," in Proceedings of the 4th International Symposium on Dioxygen Activation and Homogeneous Catalytic Oxidation, vol. 66, Elsevier Science, Amsterdam, The Netherland, 1991.

[12] J. C. Béziat, M. Besson, and P. Gallezot, "Liquid phase oxidation of cyclohexanol to adipic acid with molecular oxygen on metal catalysts," Applied Catalysis A: General, vol. 135, no. 1, pp. L7-L11, 1996.

[13] S. Kim, S. W. Bae, J. S. Lee, and J. Park, "Recyclable gold nanoparticle catalyst for the aerobic alcohol oxidation and C-C bond forming reaction between primary alcohols and ketones under ambient conditions," Tetrahedron, vol. 65, no. 7, pp. 14611466, 2009.

[14] M. L. Parentis, N. A. Bonini, and E. E. Gonzo, "Catalytic reactivity of $\mathrm{Cr} / \mathrm{SiO}_{2}$ in the liquid phase oxidation of cyclohexanol by tert-butyl hydroperoxide," Reaction Kinetics and Catalysis Letters, vol. 76, no. 2, pp. 243-248, 2002.

[15] A. Abad, P. Concepción, A. Corma, and H. García, "A collaborative effect between gold and a support induces the selective oxidation of alcohols," Angewandte Chemie-International Edition, vol. 44, no. 26, pp. 4066-4069, 2005.

[16] D. I. Enache, J. K. Edwards, P. Landon et al., "Solvent-free oxidation of primary alcohols to aldehydes using $\mathrm{Au}-\mathrm{Pd} / \mathrm{TiO}_{2}$ catalyst," Science, vol. 311, no. 5759, pp. 362-365, 2006.

[17] F.-Z. Su, Y.-M. Liu, L.-C. Wang, Y. Cao, H.-Y. He, and K.-N. Fan, "Ga-Al mixed-oxide-supported gold nanoparticles with enhanced activity for aerobic alcohol oxidation," Angewandte Chemie-International Edition, vol. 47, no. 2, pp. 334-337, 2007.

[18] B. M. Devassy and S. B. Halligudi, "Effect of calcination temperature on the catalytic activity of zirconia-supported heteropoly acids," Journal of Molecular Catalysis A: Chemical, vol. 253, no. 1-2, pp. 8-15, 2006.

[19] G. K. Chuah, S. Jaenicke, and T. H. Xu, "Acidity of high-surfacearea zirconia prepared from different precipitants," Surface and Interface Analysis, vol. 28, no. 1, pp. 131-134, 1999.

[20] Y. Nakano, T. Iizuka, H. Hattori, and K. Tanabe, "Surface properties of zirconium oxide and its catalytic activity for isomerization of 1-butene," Journal of Catalysis, vol. 57, no. 1, pp. $1-10,1979$.

[21] Y. Xu, X. Zhang, H. Li, Y. Qi, G. Lu, and S. Li, "Promotion effect of lanthanum addition on the catalytic activity of zirconia supported platinum and tungstophosphoric acid catalyst for npentane isomerization," Applied Surface Science, vol. 255, no. 1314, pp. 6504-6507, 2009.

[22] M. Ilyas, M. Sadiq, and I. Khan, "Liquid-phase oxidation of alcohols catalyzed by $\mathrm{ZrO}_{2}$ under solvent free conditions," Chinese Journal of Catalysis, vol. 28, no. 5, pp. 413-416, 2007.

[23] J. Brinksma, M. T. Rispens, R. Hage, and B. L. Feringa, "New manganese catalysts for alcohol oxidation," Inorganica Chimica Acta, vol. 337, pp. 75-82, 2002. 

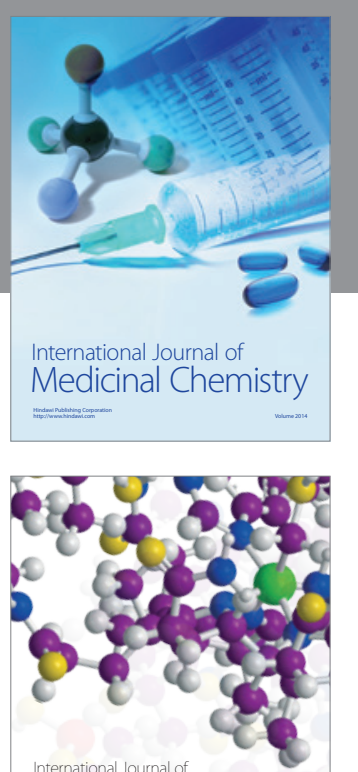

Carbohydrate Chemistry

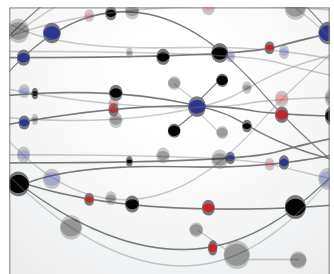

The Scientific World Journal
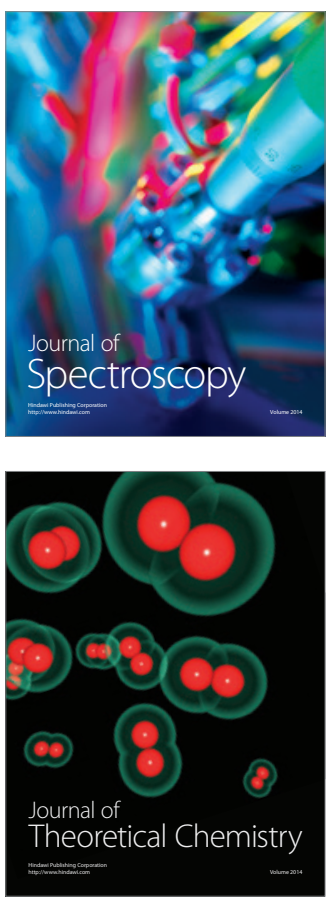
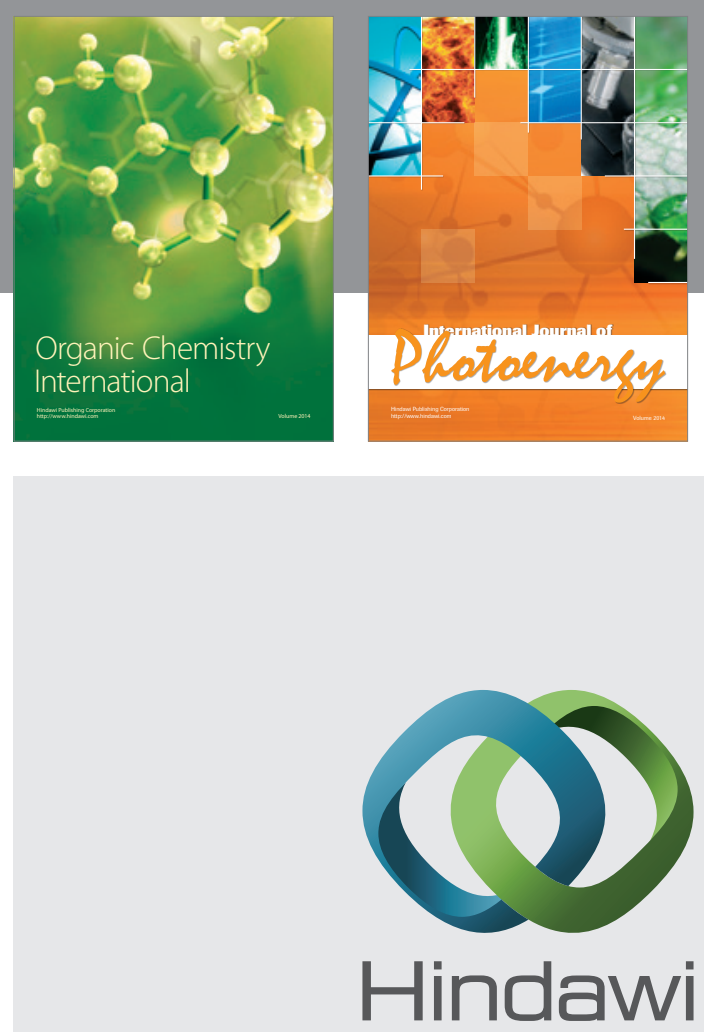

Submit your manuscripts at

http://www.hindawi.com

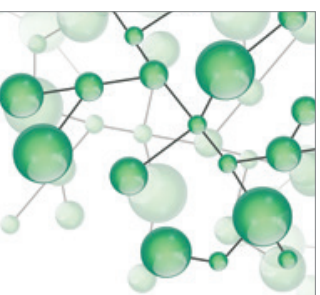

International Journal of

Inorganic Chemistry

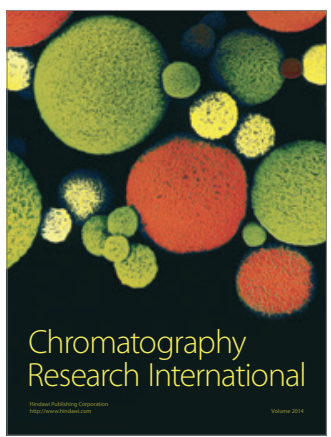

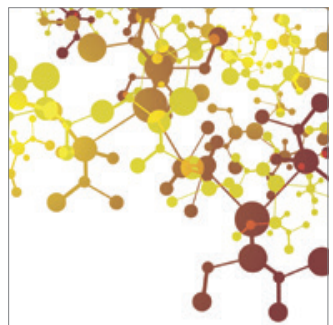

Applied Chemistry
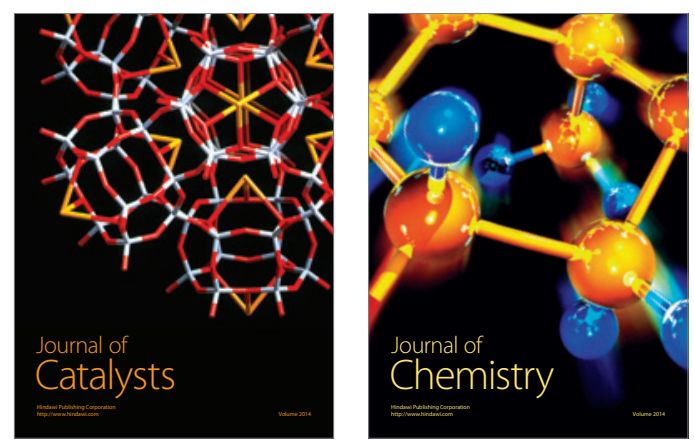
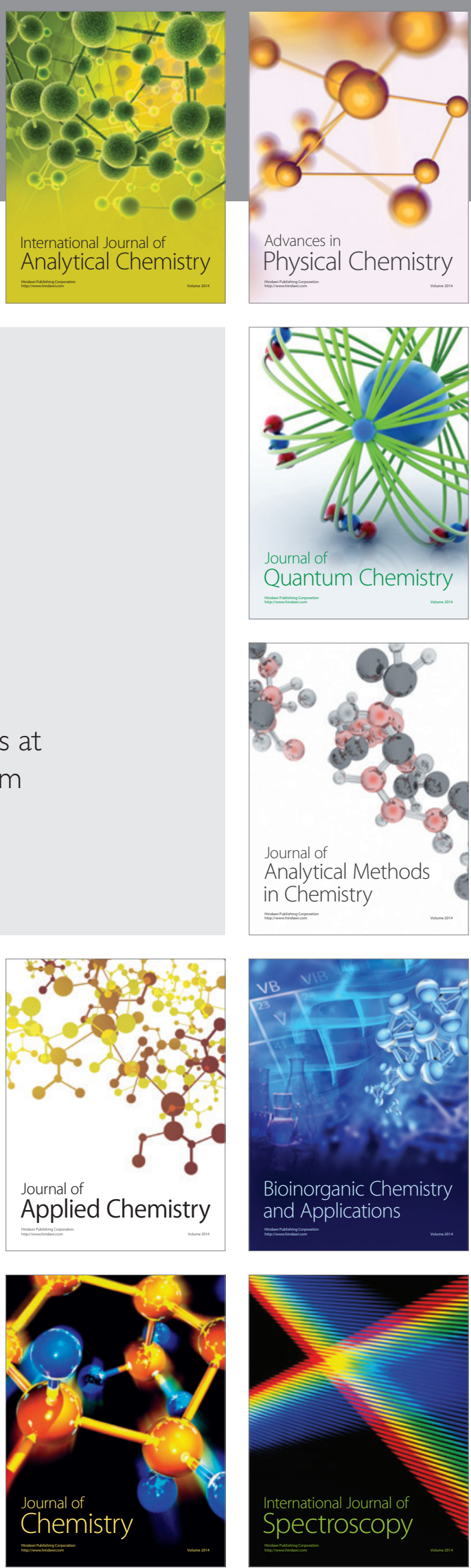